\title{
Analyzing the Behavioral Motivations BeHind IsRael's Water Conservation EFFORTS
}

KENWOO KIM AND CHARLES MORPHIS

\begin{abstract}
Israel has been at the forefront of water conservation since the 1950's. Effective water technology, management, recycling, and production allows the nation to provide water for its 9 million inhabitants, despite the limited water resources and climate. This research offers a specific look into Israel's behavioral use of water and cultural position regarding the resource while also examining multiple unique areas and their relationships. This research utilized interviews of water experts and a survey from respondents largely composed of those water experts. The results revealed Israel's religion, education, media, and interpersonal interactions all contributed to a water conscious culture that is further enforced by government centric water laws, water pricing, and technological support. These findings could provide a comprehensive guide to be utilized by future policymakers to incentivize and develop water conscious cultures within their own communities.
\end{abstract}

\section{Literature Review}

Siegal (2017) is the definitive, foundational text for this research, offering a broad but detailed view into Israeli efforts in water conservation. However, the text did not specifically address the motivating behaviors behind water conservation, and this research aims to fill this gap. Lipchin (2007), Dinar (1998), and Minahem (1998) discuss Israeli water culture, pricing, and policy respectively and are representative samples of area specific research into Israeli water usage. Yet, these texts and texts like these often omit related, broader ideas that would help further define and contextualize Israeli water behavior. For example, Lipchin (2007)

Contact: Kenwoo Kim <kenwoohkim@gmail.com> Charles Morphis<cmorphis@utexas.edu> 
provides an excellent analysis of the relationship between Israeli water culture regarding Zionism and agriculture but does not address urban water culture.

\section{Methodology}

In developing this research, 25 interviews were conducted throughout Israel from June 11th to July 8th, 2019. The majority of these interviews were conducted in English and in person. However, two interviews were conducted via phone and two other interviews were conducted in Arabic, facilitated via an experienced translator. These interviews began with a short list of fixed questions and then shifted to more pointed and specialized follow-up questions, depending on the interviewee's subject specialty. Many of the interviewees provided an expert opinion on water conservation and water policy. The majority of participants worked in academia, while others had experience in private sector water-professions, municipal government, and agriculture. A representative sample of a few key individuals include: Dr. Gideon Oron, Professor Emeritus in Ben-Gurion University of the Negev's Department of Hydrology and Microbiology; Mr. Oded Revivi, Mayor of Efrat; Mr. Hagai Ido, Chief of the Economics Department at Mekorot; and Mr. Amir "Chaki" Peleg, a cherry tomato farmer in the Western Negev.

In addition to the interviews, this research compiled a 44-question survey focused on water experts, largely composed of our interviewees, in order to consolidate several key data points and represent the opinions of an expert populace. Surveys were distributed via a digital medium and translated into Hebrew and English. From this point forward, this survey will be referred to as the expert survey.

\section{Results}

The interviews discussed a variety of topics and provided the foundation for much of this research. The main themes of these interviews can be organized into 10 areas: religion, education, media, interpersonal interactions, laws, water pricing, climate, water scarcity, history, and technology. Water pricing was mentioned the most often with $56 \%$ of interviewees discussing the subject. Technology was discussed in $44 \%$ of interviews and media followed with $36 \%$. Both education, interpersonal interactions, and water scarcity were discussed with the same frequency at $32 \%$. History was brought up in $25 \%$ of interviews and laws in $20 \%$. Religion and climate were discussed the least and were only present in $16 \%$ of interviews. 
From the expert survey, which garnered 26 responses, $52 \%$ of self-identifying respondents work in Education and Research, $14 \%$ work in private sector professions related to water policy or technology, $5 \%$ are farmers, and $29 \%$ come from other professions such as municipal officials, retirees, and blue-collar workers. The gender ratio is $58 \%$ male and $42 \%$ female, with the majority of respondents possessing a graduate degree or higher. Roughly $19 \%$ possess a high school diploma. The majority of respondents are from the age range of 41-6o, with outliers on both sides, and the next largest group being 31-40. About half of respondents come from households of $4-5$, with $23 \%$ coming from $6-7$ and $23 \%$ coming from 2-3. Only 1 respondent lives alone. The supermajority of respondents come from rural, Southern communities. Most live in the Arava, Negev, or Sinai. However, Jerusalem, Eilat, and the West Bank are represented. The supermajority of respondents are non or slightly religious Jews.

\section{Discussion}

\section{History}

Between 1929 to 1939, Britain's Mandatory Palestine experienced a large wave of Jewish immigration, bringing the population to nearly half a million people and triggering the 1936-1939 Arab Revolt. In response, British Parliament issued the White Paper of 1939 which limited Jewish immigration and land expansion in the Negev Desert. Britain cited limited water resources to justify the restriction. To refute this claim, water engineer Simcha Blass developed a comprehensive water plan for self sufficiency, outlining a blueprint to drill for aquifers in the Negev, divert rivers, and create a national water carrier (Siegel, 2017, pp. 20-27). Zionist desires to increase immigration depended on the success of the water plan. In 1946, Zionist leadership showcased the plan's feasibility by establishing permanent farms with deep drilling capabilities in the Negev and discovered aquifers. Blass further developed the Champagne Pipeline, a regional water transport system. In 1948, these actions allowed the newly formed nation of Israel to claim the sparsely inhabited Negev and open up land and resources for more immigration (Siegel, 2017, pp. 30-33). From this operation, the Zionist led survival and expansion of Israel became inextricably tied to water availability.

By the 1950s, Israel began making headway in novel water technology and practices. When no other countries considered utilizing wastewater, Israel began construction of the Shafdan sewage treatment facility in 1956, with hopes of recycling the water for future agricultural usage. Now Israel recycles over $85 \%$ of wastewater and is the leader in wastewater recycling (Siegel, 2017, pp. 78-81). 
In 1959, Simcha Blass developed micro- or drip irrigation. This novel irrigation technology utilized 50-60\% less water than conventional flood or sprinkler irrigation. Furthermore, it provided higher yields (Siegel, 2017, pp. 58-59). The nascent country embraced and widely utilized drip irrigation, setting a historical precedent for creating groundbreaking water technologies. Israel now annually exports $\$ 2.2$ billion in water technology and consultation, with a predicted potential of $\$ 10$ billion in a few years (Siegel, 2017, p. 170).

In the $1970^{\prime}$ s and $1980^{\prime}$ s, Israel faced a renewed water shortage and began reducing the consumption of water. However, water management could only mitigate the demand but not produce new sources of water. For a decade, debates to solve the issue were held, even considering importing water from Turkey, and the nation ultimately opted for large scale desalination despite high initial costs (R. Kasher, personal communication, June 18, 2019). In 1997, the first desalination plant was built in Eilat and was followed by several other plants, each larger and more sophisticated than the last. Desalination now provides the majority of municipal water in Israel and generates upwards of 600 million cubic meters of potable water per year (J. Sack, personal communication, July 3, 2019). Israel opted to pay the heavy upfront costs of desalination plants in order to provide long term, sustainable water sources. The young nation is the only country in the world to reverse desertification (O. Revivi, personal communication, June 23, 2019).

\section{Geography}

The dry climate and limited natural sources of water in Israel have deeply instilled the concept of water scarcity into Israeli society. Israel can be divided into two climates: the Mediterranean climate in the north and coastal west and the arid climate of the south. In the south, rainfall averages 1 inch annually. The cities of Sde Boker, Beersheba, Arad, and Kiryat Gat represent the northern portion of the arid south, with higher annual rainfall, but only receive 3-10 inches of rain per year. A minimum of 20 inches of water or $6000 \mathrm{~mm}$ per hectare per year is needed to grow crops in this region, requiring farmers to draw water from other sources (G. Oron, personal communication, June 11, 2019). Southern Israel is a desert, with scarce precipitation that makes rain a notable event of celebration and rarity (J. Zvuloni, personal communication, June 17, 2019). In the desert town of Merhav Am, the residents collectively remember the last major rainstorm that occurred over a decade ago. All activity ceased, with schools releasing students early, and children and adults alike collectively embracing the puddles, streams, and rainfall formed by the passing storm (O. Ben Zeev, personal communication, June 30, 2019). 
The Sea of Galilee, or locally known as the Kinneret, is one of the few large sources of surface freshwater in the nation. As one of the few visible sources of water, the Kinneret once provided $20 \%$ to $25 \%$ of the nation's drinking water and is a symbol of survival, even maintaining religious importance to this day (O. Nir, personal communication, June 26, 2019). The Coastal Aquifer, Mountain Aquifer, and Negev and Arava Aquifer are the primary sources of groundwater, but the aquifers, Kinneret, and precipitation alone cannot sustain Israel's current population. Life in Israel is only possible through water conservation practices, recycled wastewater, and desalination. The Mediterranean climate of the north and coastal west experience rainless summers but short rainy winters. The majority of rainfall in Israel occurs between November and March with the majority falling in this northern region. In short, Israel has limited water resources, requiring strong measures to encourage conservative use.

\section{Culture}

Cultural influences play an enormous role in Israelis' day-to-day water consciousness and conservation practices. They indirectly and directly alter Israeli behavior to use less water and to further seek new avenues to save water. Cultural effects can be broken down into the areas of religion, education, media, and interpersonal interactions.

Much like its history, Israel's water conscious culture stems from its religious teachings. A telling quote from Seth Siegal's Let There Be Water draws a connection of Judaism and water, " 'Rain' is not only mentioned nearly one hundred times in the Jewish holy book, but there are even specific Hebrew words - still in use in modern Hebrew - for the first and last rainfalls of the year. If Eskimos have multiple words for snow because of its constant presence, Jews in the Holy Land would seem to have several words for rain because of its scarcity." In Judaism, prayers for rain can be invoked in times of drought and hold importance on religious holidays, such as Shemini Atzeret in which a prayer marks the inception of the rainy season. Rain's importance in Israeli society even produces specific and unique prayers to the nation. One such prayer translates to "don't look into the prayers of the ones who are walking," and essentially asks to ignore prayers of people outside who want to avoid rain (E. Av, personal communication, July 2, 2019). Beyond rain, water has been tied to important religious figures. Influential 1st century Jewish scholar Rabbi Akiva was inspired to study the Torah after observing water droplets erode a hole into a rock and concluding if water had the power to steadily dissolve rock, he could have the diligence to study Judaism at the age of 40. In the Jewish Bible, it is believed that when the Messiah arrives, Israel will have plenty of water (O. Ben Zeev, personal communication, June 30, 
2019). Rain prayers and religious figures' association to water are only two of the many facets of how Judaism values water. This religion provides a basis of respecting water as a resource that can be further developed through education.

In Israel's education system, children are socialized to respect and embrace water conservation, especially at an early age. From the expert survey, $61 \%$ of respondents received a curriculum on water conservation for at least 1 or more years during their formal schooling. Of this $61 \%, 25 \%$ had 4 or more years of water conservation education, with one respondent receiving at least 8 years of formal schooling on the topic. This curriculum occurs heavily in early education and can manifest in several forms. This education can be direct, where teachers instruct students to save water on everyday tasks such as brushing teeth, or it can be more creative. Children from kindergarten through grade school are taught songs valuing water as a resource, with lyrics admonishing water loss, "it's a shame of every drop, don't waste water" (O. Ben Zeev, personal communication, June 30, 2019). Lyrics from a popular kindergarten song titled "a pity on any drop" are commonplace and emphasize the act of saving water so everyone can have equal access to it $(\mathrm{O}$. Ben Zeev, personal communication, June 30, 2019). Schools further promote a water conscious culture in a myriad of methods and their effects extend beyond students. In the city of Efrat, Mayor Oded Revivi specifically utilizes young children to enact city wide change. "So first of all, generally speaking, kids are the best change agents. If I want to do something or educate my residents to recycle more things, I will always go to the lowest grade, the youngest kids in the education system. I have to invest in them the least amount of time and they can be my quickest, most effective change agents." In one instance, Mayor Revivi sent kindergarteners home with a clock that had the time and cost of water based activities. These activities included items such as the price of showering for 5 minutes, brushing teeth for 2 minutes, and flushing the toilet. Revivi aimed to instill ideas of water consciousness at a young age while also encouraging households to save water (O. Revivi, personal communication, June 23, 2019). Early water education in kindergarten holds a central theme in Israeli education and some teachers even go to great lengths to instill a fear of water scarcity or irresponsible water use. In the small desert town of Merhav Am, students recall teachers scaring them to save water with warnings that the water will run out if they waste it. Teachers would often tell kindergarteners the value of saving water and instill practices such as finishing water bottles when playing outside (O. Ben Zeev, personal communication, June 30, 2019). Water education, particularly for young students, takes on many forms and instills the need to save water.

Early formal education in water conservation is supplemented by frequent exposure to water topics through media. In the expert survey, respondents cited the media more than any other source as the largest contributor to their 
knowledge on water conservation. The Kinneret, or Sea of Galilee, holds biblical importance and is associated with the survival of Israel. Every day, radios and news broadcasts in Israel announce the rise and fall of the water level of the Kinneret. Increases in water level by even 2 to 3 centimeters elicit positive emotions while decreases elicit negative ones. Dr. Gideon Oron described a common understanding, "We have a joke, if the Sea of Galilee is full of water, then people are happy" (G. Oron, personal communication, June 11, 2019). Israelis from adolescence to adulthood constantly hear about the water level and discussions surrounding it. The Kinneret, one of the nation's most visible water assets, has become an unofficial proxy for the level of water security within the nation (G. Oron, personal communication, June 11, 2019).

Television plays a major role in swaying public opinion and creating memorable impressions. In the late 2000's, the Israeli government launched a television-based campaign titled "Israel is drying out" to compel Israeli citizens to use less water. The most prominent ad featured supermodel Bar Rafaeli with her skin drying out as she discusses Israel's water issues. This single television ad was mentioned in multiple of our research interviews and a significant portion of Israelis recognize and remember the ad to this day (E. Av, personal communication, July 2, 2019; O. Ben Zeev, personal communication, June 30, 2019; J. Zvuloni, personal communication, June 17, 2019). The success of the campaign led the Israeli government to air another ad in 2014 starring Bar Rafaeli and warn that Israel still faces water shortages despite advances in desalination (E. Av, personal communication, July 2, 2019). Television campaigns have existed for decades and early campaigns in the 1970's through the 1990's had different approaches. Some served more as informative commercials on saving water, giving advice such as how to wash a car or when to water a garden $(\mathrm{O}$. Ben Zeev, personal communication, June 30, 2019). Others had targeted audiences such as children. One had featured a young boy brushing his teeth and showering, with the child shouting a slogan at the end "in the meantime close the [faucet]" (E. Av, personal communication, July 2, 2019). The government also utilized other mediums such as the Internet and newspapers to communicate similar ideas; however the efficacy of these methods is unknown (N. Levy, personal communication, June 19, 2019). Public campaigns have also used other nontraditional mediums such as placing stickers in public restrooms advising to turn off the faucet (J. Zvuloni, personal communication, June 17, 2019). These campaigns are so pervasive and widespread that $96 \%$ of the expert survey respondents have seen an advertisement about water conservation.

Interpersonal interactions and personal experiences offer further socialization into water conservation values. Parents are often children's first introduction to water conservation. Parents teach their kids to save water from closing off faucets to teaching them songs about the value of one cup of water $(\mathrm{O}$. Ben Zeev, 
personal communication, June 30, 2019; J. Zvuloni, personal communication, June 17, 2019). In the expert survey, parents were the 2nd largest contributor to water conservation education, falling one respondent short of media. Israelis caution visiting foreigners to save water and when Israelis go abroad, they have been known to admonish others for wasting water, even in water abundant countries (N. Avieli, personal communication, June 26, 2019). Nearly 1/3rd of the expert survey respondents claim to feel judged when their peers perceive them to waste water. Israeli couples can even get into arguments over excessive water use (H. Ido, personal communications, June 24, 2019). Israelis self support a water conscious culture to effectively teach or pressure others to utilize water efficiently and conservatively. This culture is strong enough to elicit physical and emotional distress when Israelis see water loss. One sociologist describes the emotion, "I can not see something like this. I am angry when my kids waste water. I don't like it. I feel pain in my body when I see [it] because I was educated in this way" (N. Avieli, personal communication, June 26, 2019).

Religion, education, media, and interpersonal interactions produce a nation that highly values water as a resource. From birth to adulthood, Israelis are constantly barraged by messages to conserve water and this engenders a culture of water consciousness, therefore altering behavior. This consciousness manifests itself into practices, knowledge, and beliefs seen in the expert survey. The following statistics have all been derived from the expert survey. In terms of practices, a supermajority of respondents say their showers are less than $10 \mathrm{~min}-$ utes, with $39 \%$ saying they are less than 5 minutes. On top of this, $69 \%$ say they only wash their car every other month or less, being less than 6 times per year. Of these, most say they only wash their car 3 times per year. In terms of knowledge, $68 \%$ correctly say farmers are the largest consumers of water and $81 \%$ are confident that they know and understand the source of their drinking water. Although Israel holds many global achievements for its efforts in water conservation and reuse, Israelis believe there remains much room for individual improvement. When asked how often they conserve water when presented the opportunity, only $27 \%$ said "every time." A majority of $58 \%$ said "most of the time." Despite Israel's significant advancement in water conservation, individuals still believe that more can be done. For further evidence, $89 \%$ of respondents said they can definitely do more to conserve water in their everyday lives. A more revealing facet: the majority of Israelis adamantly believe water is a scarce, finite resource. A supermajority of $73 \%$ of respondents believe that past generations used less water than we do today. The belief that there is an ever increasing amount of water usage is coupled with the belief that water is a depleting, finite resource. To add to this belief, $39 \%$ of respondents believe that in the next 25 years, in their area, there will be a "considerable shortage" of water. Overall, about $70 \%$ of respondents believe that there will not be enough water to meet demands in 
that time frame. No respondents claimed that there will be "more than enough" water to meet future demands in that time frame. When asked about their concern for immediate water shortage, $39 \%$ of respondents claimed to be moderately worried ( 3 on a $1-5$ scale), with $12 \%$ being very worried (5 on a $1-5$ scale). Only $19 \%$ claimed to not be worried at all.

\section{Government and Economics}

While culture creates a self-perpetuating consciousness of water conservation, the government can provide the basis to enforce and guide such a culture. Water laws, pricing, and programs modify behavior to ultimately reduce water usage. Additionally, the Israeli government has taken proactive measures to steer public behavior and allocate funds to invest in water technologies.

Laws pertaining to the ownership of water allow the Israeli government to forcibly implement water saving practices. Israel's Parliament, the Knesset, passed the Water Law of 1959 which gave the government "widespread power to control and restrict the activities of individual water users in order to further and protect the public interest" (Siegel, 2017, p. 17). The Water Law of 1959 and the laws that led up to it effectively gave the government control over all water resources. The law granted the government control over water in privately owned lands and gave government ownership to every drop of rain. Unlike the US, where an individual may own the source of a river or aquifer if they own the surrounding land, Israel allows the government to maintain ownership of the mineral rights to any water source throughout the country. Making water a public resource allowed the Israeli government to make sweeping infrastructure changes, diverting water to much needed areas and using sources of water sustainably. This law has greatly shaped Israeli water usage as its legal precedence has given rise to many other water laws. In terms of directly limiting citizen's water usage, the government passed laws to mandate water saving technologies in consumer and commercial usage. In urban areas, the average Israeli consumes 100 liters of water a day and about half of this is used for toilet water. The government required the installation of dual flush toilets which offer a liquid waste flush option to decrease water usage per flush by half (J. Sack, personal communications, July 3, 2019). The same logic has been applied to water faucets. All water faucets in Israel are required to have aeration filters which have the potential of reducing water usage up to $70 \%$ (J. Zvuloni, personal communication, June 17,2019 ). These types of laws offer an explanation as to why $57 \%$ of the expert survey respondents have appliances such washing machines or dishwashers that are water-efficient and why $88 \%$ use drip irrigation. Beyond technological mandates, the government also has laws concerning direct water usage, 
such as preventing irrigation of grass in particularly dry areas or prohibiting car washes with hoses in times of drought.

Due to the widespread laws regarding water ownership, the government directly controls the pricing of water, and pricing coercively enforces water conservation. Mekorot is the national water utility company of Israel and controls the National Water Carrier, the main pipeline which distributes water throughout the nation to municipally-owned, local utilities or "water distributors." Mekorot, as a "national monopoly," must operate alongside the distributors under a legal mandate in which end users or consumers pay the same price nationwide. "All customers should pay the same tariff for water, regardless of where they are ... Farmers in the north could have free water, [but] they still have to pay for the water they take, and by [doing] that, they subsidize the farmers down in the south, which are obviously paying much less than the real cost of the water [they receive] $(\mathrm{H}$. Ido, personal communications, June 24, 2019). Israel is able to adopt this admittedly unique water supply chain due to its small geography and ability to use a single company, Mekorot, as a benchmark for pricing water nationwide. This end user price is determined by an independent government regulator, using Mekorot's projected national expenses, and remains fixed regardless of the particular transportation costs to supply a certain area.

Mekorot acts as a national, government-owned monopoly with the sole right to purchase water from the government and supplies water in bulk to the city and municipal utilities. The water distributors then in turn provide water to their citizens. This system works by having consumers pay local distributors a nationally set rate for water, and the distributors then pay Mekorot a percentage for the water their municipality consumes. This percentage changes depending on the municipality's access to water. For example, Tel Aviv, having easier access to water, might pay $90 \%$ of each shekel it receives from its consumers back to Mekorot, whereas Jerusalem might only pay 50\% (H. Ido, personal communications, June 24, 2019). Without any government subsidies, these companies must act similar to private sector firms while also completing their legal mandates. The companies must manage their expenses and revenues within the narrow realm that the government provides between the wholesale cost of water and the end user purchase price. This encourages firms to diligently monitor their water usage and invest in water saving technologies.

In this system, citizens with easy access to water are paying more than the cost to receive it, and the price is substantial enough to discourage waste in areas with relatively plentiful water. This also prevents water from being prohibitively expensive in the desert and remote regions of Israel, encouraging agriculture and migration to these regions $(\mathrm{H}$. Ido, personal communications, June 24, 2019). However, this true price of water brings with it dissatisfaction, with $50 \%$ 
of expert survey respondents believing end users should not have to bear the full price of water. Furthermore, Israel uses block rate pricing, drastically increasing prices after a set allotment of water is used. On average, each person receives 1 to 2 cubic meters per month and each household has 8 to 10 cubic meters per month at the initial price (N. Avieli, personal communication, June 26, 2019). The initial price is typically 2 to 3 shekels per cubic meter. However, after the initial allotment, the next allotment could potentially be 5 shekels per cubic meter and then to 10 shekels after that, continually increasing (O. Ben Zeev, personal communication, June 30, 2019). This same style of pricing is applied to agriculture, albeit subsidized to roughly $1 / 3$ rd of the household water price, but the price still remains significant enough to be $5 \%$ to $7 \%$ of operating expenses. In moshavim, cooperative agricultural towns, the price and amount of the initial water allotment can be severe enough to cause the entire moshav to limit crop planting (A. Peleg, personal communications, July 3, 2019).

The government also engages in less forceful ways to ensure water conservation, providing incentives and support. The government funds and hosts water specific technology incubators which encourage entrepreneurial innovation. For two years, these incubators provide inventors financial, technical, and business support to produce a prototype of their invention. Once the prototype is completed, it is up to the inventor to then market, produce, and sell their invention. These inventors typically turn to venture capitalists or angel investors to start refinement and production of their invention. If the inventor is successful, the Israeli government support is seen as a loan and the costs are expected to be paid back. If the inventor fails, the support is seen as a grant. These incubators provide inventors a low risk and high reward system to produce water saving or generating technologies such as new water filtration systems. This process is further facilitated because the Israeli government hosts water technology conferences to share ideas and connect inventors to investors. In the early 2000's, Israel hosted the Water Technology and Environmental Control convention, gathering thousands of participants in its first year, and conferences have continued to be a forum to support Israeli inventors (J. Gilron, personal communications, June 20, 2019). Aside from technology, the government provides industry specific subsidies to reduce water usage. For example, in the water intensive fruit industry, the government provides further water subsidies if the growers did not exceed a set amount of water consumption. This has proven to reduce water usage by $35 \%$ to $40 \%$, and this method rewards, rather than punishes, agricultural producers (J. Sack, personal communication, July 3, 2019). The Israeli government engages in a variety of unique methods to save water, operating with both a cost and reward system.

The firm approach by the Israeli government could potentially be interpreted as overbearing but according to the expert survey data, Israeli citizens expect 
even more measures from their government. With $73 \%$ of respondents claiming to understand government plans to address future water needs, Israelis are aware of their government's efforts with water conservation and resources. With this awareness, 96\% of respondents agree nationwide funding should be used to implement water conservation strategies. This knowledge coupled with this belief explains why Israelis are calling for more government effort. For reference, $46 \%$ of respondents said that they are not content with the Israeli government's current attempts to conserve water. A sizable $89 \%$ say their local water utility is not doing enough to educate the public on means to conserve water and $50 \%$ claim that they are not even aware of any water conservation efforts from their local government.

\section{Further Discussion and Future Research}

A primary point for further study is the longevity of this water consciousness. In the early 2000's, Israel raised the cost of water, in addition to the block rate pricing, to reflect the actual economic costs and for the first 10 years of implementation, water usage drastically lowered. However, the last few years have shown an overall increase in water consumption per capita, indicating households are becoming accustomed to higher water bills and are therefore using more water (H. Ido, personal communications, June 24, 2019). To add to this concern, some Israelis have seemingly adopted a penchant for the American lifestyle with a tendency to cultivate water intensive grass lawns and to have A-frame roofs suited for heavy snow/rain, an unnecessary use of resources considering many of these houses are in the desert (N. Avieli, personal communication, June 26, 2019). Furthermore, the addition of desalination plants as a novel source of water has initiated a cultural shift in which Israelis see water as plentiful and no longer scarce, despite existing needs to continue water conservation (N. Levy, personal communication, June 19, 2019). To reference a previous statistic, 19\% of the expert survey respondents are not worried at all about an immediate water shortage, and this percentage has the potential to grow. Israel's excellent capacity to recycle and desalinate water were not talked about in length in this discussion, but their effects on future behavior could end Israel's headway as the global leader on water conservation.

\section{Conclusion}

By pairing a self-supporting culture to centralized pricing and governance, Israel has developed an effective strategy to encourage water conservation. The nation 
has utilized these methods to achieve and maintain its position as the global leader in water conservation and reuse for decades. Israel's approach to encouraging water conservation is a valuable lesson to policymakers and organizations aiming to promote water sustainability. Two methods in particular could benefit decision makers because of their effectiveness and replicability: water pricing and cultural exposure. From the research interviews, over half of interviewees noted that water pricing is a key strategy in influencing water conservation. This strategy is largely the most visible and impactful to consumers. However, appropriate water pricing does not have to stem from a national monopoly system as it does in Israel. This strategy can be achieved through initiatives at the local water utility level, as has been done in El Paso. In the dry, Texas town, the local utility works in unison with the local government to enforce a series of penalties and rewards surrounding water use (Schlanger, 2018). In addition to water pricing, $30 \%$ of expert survey respondents cited the media as their primary channel for learning about water conservation. Following this statistic, $27 \%$ of expert respondents cited their parents as their primary educator on water conservation and $23 \%$ cited their friends. Lastly, $15 \%$ of expert respondents cited education as their primary means for learning about water conservation. These statistics indicate a cyclical culture in which water consciousness permeates generations of society. Government or NGO-backed initiatives showcase water conservation in the media and work alongside formal schooling on the topic to educate the populace. When publicized in meaningful and appropriate volumes, the initiatives develop a water conscious culture which transcends from generation to generation. These two strategies, centralized pricing and cultural exposure, form a powerful combination which influences both the economic use and the societal value of water.

However, these strategies are unlikely to come about in many countries unless the incentive exists for these countries to adopt these strategies. Legal reforms require both economic and political capital, and the high price of adopting a coherent water conservation strategy will be too much for many countries without an urgent need arising. Israel has faced this need for decades as a country located in an arid climate with a continuing threat of desertification. Similar communities such as West Texas or the Southwestern United States might find themselves facing this threat and could be incentivized to follow Israel's lead in water conservation. El Paso has already begun this process by investing in desalination and purification technology, promoting water conservation exposure through the media, and enforcing local ordinances to conserve water. One such program adopted by the El Paso Water Utility is 'Willie the Water Drop,' a city mascot who visits schools and teaches children about the importance of saving water (Schlanger, 2018). Experts from Israel facilitate much of this technological and cultural exchange. 
This research has identified several major themes which communities or countries might use to encourage water conservation, however, much of our findings remain qualitative and anecdotal. Our interviews utilize the experience and knowledge of a select group of experts and professionals in the field of Israeli water conservation, but these individuals are not enough to statistically represent the entire nation of Israel or a cohesive opinion of water professionals globally. In order to further solidify which methods are most effective in terms of encouraging water conservation, further quantitative research is needed. Still, these findings represent the qualitative history and attitude of many in the nation of Israel and provide a thorough look into the consciousness surrounding Israeli water conservation.

In conclusion, Israel has created a culture and societal consciousness which preserves and conserves water resources, modifying behavior directly or indirectly through religion, education, media, and interpersonal interactions. The nation has further advanced water conservation by establishing laws requiring the protection and conservation of the asset, pricing that discourages water use, and programs to develop the next generation of water saving technology. However, the same technologies and practices which have allowed Israel to become a global leader in water conservation could very well lead the country to increase its water usage and diminish its cultural focus on water conservation. These are all important lessons for future policymakers to keep in mind when embarking on new water conservation initiatives.

\section{References}

Av, E. (2019, July 2). Phone interview.

Avieli, N. (2019, June 26). Personal interview.

Ben Zeev, O. (2019, June 30). Personal interview.

Dinar, A. (1998). Policy implications from water pricing experiences in various countries.

Water Policy, 1(2), 239-250. doi: 10.1016/s1366-7017(98)00011-7

Gilron, J. (2019, June 20). Personal interview.

Ido, H. (2019, June 24). Personal interview.

Kasher, R. (2019, June 18). Personal interview.

Levy, N. (2019, June 19). Personal interview.

Lipchin, C. (2007). A Future for the Dead Sea Basin: Water Culture among Israelis, Palestinians and Jordanians. Water Resources in the Middle East, 2, 87-107. doi: 10.1007/978-3-540-69509-7_9

Menahem, G. (1998). Policy Paradigms, Policy Networks and Water Policy in Israel. Journal of Public Policy, 18(3), 283-310. doi: 10.1017/so143814x98000142

Nir, O. (2019, June 26). Personal interview.

Oron, G. (2019, June 11). Personal interview.

Peleg, A. (2019, July 3). Personal interview. 
Revivi, O. (2019, June 23). Personal Interview.

Sack, J. (2019, July 3). Personal interview.

Schlanger, Z. (2018, August 23). El Paso is on the Cutting Edge of Water Conservation. It Really Has No Choice. Retrieved June 28, 2020, from https://www.texasobserver. org/el-paso-is-on-the-cutting-edge-of-water-conservation-it-really-has-no-choice/

Siegel, S. M. (2017). Let there be water: Israel's solution for a water-starved world. New York: Thomas Dunne Books, an imprint of St. Martin's Press.

Zvuloni, J. (2019, June 17). Personal interview. 